\title{
Feed additives containing sequestrant clay minerals and inactivated yeast reduce aflatoxin excretion in milk of dairy cows
}

\author{
R. O. Rodrigues, ${ }^{1 *}$ R. O. Rodrigues, ${ }^{1}$ D. R. Ledoux, ${ }^{1}$ G. E. Rottinghaus, ${ }^{2}$ R. Borutova, ${ }^{3}$ O. Averkieva, ${ }^{3}$ \\ and T. B. McFadden ${ }^{1} \dagger$ \\ ${ }^{1}$ Division of Animal Sciences, University of Missouri, Columbia 65211 \\ ${ }^{2}$ Department of Biomedical Sciences, University of Missouri, Columbia 65211 \\ ${ }^{3}$ Nutriad International NV, Hoogveld 93, 9200 Dendermonde, Belgium
}

\section{ABSTRACT}

The objective was to evaluate the efficacy of 2 dietary mycotoxin sequestrants, Toxy-Nil (TN) or Unike Plus (UP), in reducing aflatoxin (AF) $\mathrm{M}_{1}$ concentrations in milk of dairy cows challenged with dietary AF. Thirtytwo mid-lactation Holstein cows were blocked by parity, days in milk, and milk yield and were randomly assigned within block to receive one of the following treatments: (1) $2.8 \mathrm{mg}$ of $\mathrm{AF} / \mathrm{cow}$ per d (positive control, PC), (2) $2.8 \mathrm{mg}$ of $\mathrm{AF}+100 \mathrm{~g}$ of $\mathrm{TN} /$ cow per d, (3) 2.8 $\mathrm{mg}$ of $\mathrm{AF}+100 \mathrm{~g}$ of $\mathrm{UP} /$ cow per d, or (4) no $\mathrm{AF}$ and no additives (negative control, NC). For $7 \mathrm{~d}$, treatments, dispersed in $150 \mathrm{~g}$ of sweet feed carrier, were top-dressed twice daily by mixing into the top portion of the TMR at each feeding. After the experimental period, cows were fed the NC diet and clearance of $\mathrm{AFM}_{1}$ via milk was monitored for $7 \mathrm{~d}$. Feed and water were available ad libitum throughout the trial. Treatments had no effect on feed intake, milk yield, milk composition, or milk somatic cell count. Relative intake of AF was similar among PC, TN, and UP, averaging $106.5,107.6$, and $102.5 \pm 2.9 \mu \mathrm{g} / \mathrm{kg}$ of diet dry matter, respectively. Relative intake of mycotoxin sequestrants was similar between TN and UP, averaging 0.4 and 0.4 $\pm 0.1 \%$ of diet dry matter, respectively. Concentration and mass of $\mathrm{AFM}_{1}$ secreted in milk and in urine were similar between TN and UP, but were lower than PC; concentrations in milk averaged $0.2,0.3$, and $0.6 \pm 0.1$ $\mu \mathrm{g} / \mathrm{kg}$, respectively, and mass secreted in milk averaged $8.1,9.8$, and $20.5 \pm 1.7 \mu \mathrm{g} / \mathrm{d}$. Concentrations in urine averaged $6.9,7.4$, and $14.2 \pm 1.5 \mu \mathrm{g} / \mathrm{L}$, respectively, and mass secreted in urine averaged $225.7,250.8$, and $521.6 \pm 53.1 \mu \mathrm{g} / \mathrm{d}$. Likewise, concentration and mass of free $\mathrm{AF}$ excreted in feces were similar between $\mathrm{TN}$

Received December 11, 2018

Accepted February 26, 2019.

* Present address: Department of Animal Production, Sao Paulo State University, Botucatu 18168-000, Brazil.

†Corresponding author: mcfaddent@missouri.edu and UP, but were lower than PC; concentrations averaged $7.7,8.9$, and $12.4 \pm 0.6 \mu \mathrm{g} / \mathrm{kg}$, respectively, and mass excreted averaged 57.8, 69.6, and $95.6 \pm 4.8 \mu \mathrm{g} / \mathrm{d}$. Transfer of AF from feed to $\mathrm{AFM}_{1}$ in milk was reduced by 63 and $52 \%$, and in urine, by 57 and $52 \%$ for TN and UP, respectively. Transfer of AF from feed to free $\mathrm{AF}$ in feces was reduced by 38 and $26 \%$ for TN and UP, respectively. The clearance rate of $\mathrm{AFM}_{1}$ in milk did not differ among PC, TN, and UP (46.1, 66.5, and 50.0 $\pm 6.7 \% / \mathrm{d}$, respectively). Results indicate that dietary inclusion of $100 \mathrm{~g}$ of TN or UP significantly reduced $\mathrm{AFM}_{1}$ in milk of cows consuming TMR containing approximately $105 \mu \mathrm{g}$ of $\mathrm{AF} / \mathrm{kg}$ of diet dry matter. Results also suggest that both TN and UP reduced absorption of AF.

Key words: adsorbent, aflatoxin $\mathrm{M}_{1}$, mycotoxin

\section{INTRODUCTION}

Aflatoxins (AF) are mycotoxins produced by several species of fungi. Of particular interest in livestock feed are those of the genus Aspergillus, present in 20 to $30 \%$ of feeds globally (Streit et al., 2013), and estimated to exceed $\$ 250$ million in annual costs to crop and livestock operations in the United States alone (Richard et al., 2003). Aflatoxin $B_{1}$ is the major AF produced and it is considered the most toxic naturally occurring toxin (Squire, 1981; Bennett and Klich, 2003). It is quickly absorbed in the upper gastrointestinal tract of animals due to its low molecular weight (312 Da; Yiannikouris and Jouany, 2002; Moschini et al., 2007; Gallo et al., 2008), being detected in plasma of dairy animals by 5 min after ingestion (Gallo et al., 2008). After absorption, $\mathrm{AFB}_{1}$ is metabolized in the liver by the cytochrome P450 system, forming $\mathrm{AFM}_{1}$ (Kuilman et al., 2000), a hepatotoxin and immune suppressor (Wogan, 1999; Jiang et al., 2005) classified as a group 1 carcinogen by the International Agency for Research on Cancer (IARC, 2002). Aflatoxin $\mathrm{M}_{1}$ has been detected in milk and urine by $6 \mathrm{~h}$ after ingestion of $\mathrm{AFB}_{1}$ (Helferich et al., 1986; Battacone et al., 2003). 
Challenging dairy cows with dietary $\mathrm{AFB}_{1}$ has been shown to reduce milk yield (Applebaum et al., 1982), milk protein concentration, and milk fat yield (Queiroz et al., 2012). Furthermore, $\mathrm{AFB}_{1}$ diminished cellular and humoral immune responses of toxin-fed pigs (Marin et al., 2002) and increased incidence of fatty liver and degeneration and necrosis of liver cells in rats (AbdelWahhab et al., 2002). In the United States, the Food and Drug Administration (FDA) has set limits for AF in feed $(20 \mu \mathrm{g} / \mathrm{kg})$ and for $\mathrm{AFM}_{1}$ in milk $(0.5 \mu \mathrm{g} / \mathrm{kg})$; in Europe, milk concentrations of $\mathrm{AFM}_{1}$ may not exceed $0.05 \mu \mathrm{g} / \mathrm{kg}$ (FDA, 2000; EFSA, 2004).

Various compounds with adsorbent characteristics have been evaluated as potential dietary additives to reduce absorption of AF. Examples of such toxin-binding compounds include bentonite, kaolin, montmorillonite clays, hydrated sodium calcium aluminosilicate, and glucomannan (Ramos and Hernández, 1997; AbdelWahhab et al., 2002; Diaz et al., 2002; Queiroz et al., 2012; Carraro et al., 2014). These adsorbents bind to dietary $\mathrm{AFB}_{1}$, making it unavailable for absorption, and thereby reducing formation of $\mathrm{AFM}_{1}$ and its secretion into milk (Moschini et al., 2008; Gallo and Masoero, 2010; Queiroz et al., 2012). The ability of these compounds to reduce $\mathrm{AFM}_{1}$ in milk is related both to level of inclusion of the products in the diet and to the concentration of AF that is supplied to the cows (Diaz et al., 2004; Kutz et al., 2009; Ogunade et al., 2016). Moreover, there are indications of effects of $\mathrm{AFB}_{1}$ or the adsorbents, themselves, on milk production, rumen fermentation, and immune status, but responses have been inconsistent. For example, supplementation of an $\mathrm{AF}$ adsorbent to dairy cows challenged with AF did not affect mammary, liver, or immune function, but altered rumen characteristics in the presence or absence of dietary AF (Xiong et al., 2015). In contrast, feeding $\mathrm{AF}$ tended to reduce milk fat yield and alter some indicators of immune status, but effects of supplemental adsorbents on those variables and $\mathrm{AFM}_{1}$ concentrations in milk were inconsistent (Queiroz et al., 2012; Ogunade et al., 2016).

Thus, different studies have reported various levels of efficacy, depending on AF dosages and adsorbent compounds tested, and several studies have emphasized the need for further experimentation. We hypothesized that dietary supplementation of lactating dairy cows fed an AF-contaminated diet with either of 2 different mycotoxin sequestrants would reduce $\mathrm{AFM}_{1}$ concentrations in milk and urine, without affecting milk production. Our objective was to establish and compare the efficacy of 2 dietary mycotoxin sequestrants, TN or UP, on reducing transfer of $\mathrm{AF}$ from diet to milk and on production of lactating dairy cows challenged with an AF-contaminated diet.

\section{MATERIALS AND METHODS}

\section{Animals, Experimental Design, and Treatments}

The experiment and use of animals was approved by the University of Missouri Animal Care and Use Committee (protocol number 8706). Thirty-two midlactation Holstein cows $(35.7 \pm 4.5 \mathrm{~kg} / \mathrm{d}$ of milk, 183 \pm 70 DIM, and $2.1 \pm 0.7$ lactations; mean \pm SD) housed in a free-stall facility at University of Missouri Foremost Dairy Research Center were blocked based on DIM, milk yield, and parity. The experiment was conducted as a complete randomized block design, with cow as the experimental unit. Cows within block were randomly assigned to receive 1 of 4 treatments: (1) 2.8 $\mathrm{mg}$ of $\mathrm{AF}$ (positive control, PC), (2) $2.8 \mathrm{mg}$ of AF + $100 \mathrm{~g}$ of Toxy-Nil (TN; Nutriad Animal Feed Additives, Dendermonde, Belgium), (3) $2.8 \mathrm{mg}$ of $\mathrm{AF}+100$ $\mathrm{g}$ of Unike Plus (UP; Nutriad), or (4) no AF and no additives (negative control, NC). Dietary AF was supplied as Aspergillus parasiticus (NRRL-2999) culture material containing $650 \mathrm{mg} / \mathrm{kg}$ of $\mathrm{AFB}_{1}, 22 \mathrm{mg} / \mathrm{kg}$ of $\mathrm{AFB}_{2}, 223 \mathrm{mg} / \mathrm{kg}$ of $\mathrm{AFG}_{1}$, and $5.7 \mathrm{mg} / \mathrm{kg}$ of $\mathrm{AFG}_{2}$. Toxy-Nil is composed of high adsorbent clay minerals and inactivated yeast (Saccharomyces cerevisiae), and Unike Plus is composed of high adsorbent clay minerals, inactivated yeast (S. cerevisiae), botanical components, and a mixture of antioxidants and preservatives. Treatments were dispersed into $150 \mathrm{~g}$ of sweet feed carrier (Non-Medicated Calf Grower, MFA Agri-Services, Columbia, MO) and top-dressed by mixing into the top portion of the TMR at each twice-daily feeding.

The trial consisted of three 7-d periods, which included an initial period for adaptation to grouping, pen housing, and feeding system ( $\mathrm{d}-6$ to 0 ); an experimental period, during which $\mathrm{AF}$ and mycotoxin sequestrants were fed to cows as per treatment design (d 1 to 7); and a recovery period, during which all cows received the $\mathrm{NC}$ diet and were monitored until levels of $\mathrm{AFM}_{1}$ in milk were undetectable (d 8 to 14 ).

\section{Cow Management}

The diet was a TMR formulated to meet or exceed predicted nutrient requirements (NRC, 2001). Cows were individually fed twice daily (1530 and $0730 \mathrm{~h}$ ) using feed bins (American Calan, Northwood, NH). Feed was available ad libitum to about $10 \%$ refusals, and intake was recorded. Feeds were sampled every 3 $\mathrm{d}$ and DM content was determined by forced-air oven drying at $55^{\circ} \mathrm{C}$ for $72 \mathrm{~h}$. Diets were adjusted weekly for DM content of ingredients. Feed samples were ground through a 2-mm sieve, combined into a single composite, and analyzed by wet chemistry for chemi- 
cal composition (DairyOne Laboratories, Ithaca, NY). The ingredient and chemical composition of the diets is shown in Table 1. Water was available ad libitum.

Cows were milked twice daily (1900 and $0700 \mathrm{~h}$ ) and milk production was automatically recorded (GEA Group AG, Düsseldorf, Germany). Milk samples for composition were collected on d 0,7 , and 14 of the trial from consecutive p.m. and a.m. milkings, then immediately refrigerated at $4^{\circ} \mathrm{C}$ with a preservative (Broad Spectrum Microtab, Advanced Instruments, Norwood, MA) until individually analyzed for fat, protein, lactose, SNF, MUN, and SCC by a certified DHIA laboratory (Mid-South Dairy Records, Springfield, MO). Milk composition for each experimental period was calculated from the composite of each milking corrected for milk yield. Energy-corrected milk and 3.5\% FCM were calculated as described by Dairy Records Management Systems (2014): ECM $(\mathrm{kg} / \mathrm{d})=($ milk yield, $\mathrm{kg} / \mathrm{d} \times$ $0.327)+($ milk fat, $\mathrm{kg} / \mathrm{d} \times 12.95)+($ milk true protein, $\mathrm{kg} / \mathrm{d} \times 7.65)$, and $3.5 \% \mathrm{FCM}(\mathrm{kg} / \mathrm{d})=($ milk yield, $\mathrm{kg} / \mathrm{d} \times 0.432)+($ milk fat, $\mathrm{kg} / \mathrm{d} \times 16.216)$. Feed efficiency was calculated as feed efficiency $=$ milk yield, ECM, or $3.5 \%$ FCM, $\mathrm{kg} / \mathrm{d} \div \mathrm{DMI}, \mathrm{kg} / \mathrm{d}$. Lastly, milk flow rate was calculated as daily milk yield divided by the combined duration of p.m. and a.m. milkings.

On d 0,7 , and 14, BW and rectal temperature were recorded immediately after the morning milking and before the morning feeding. Also, cows were independently assessed by 2 individuals for BCS and locomotion score as described by Wildman et al. (1982) and Sprecher et al. (1997), respectively, and the average of scores was used in the analyses.

Laboratory Analysis of Milk Components. Milk fat, true protein, and lactose were determined by infrared spectroscopy (Bentley 2000, Bentley Instruments, Chaska, MN), MUN by a modified Berthelot reaction (ChemSPec 150, Bentley Instruments), and SCC by flow cytometry (Somacount 300, Bentley Instruments) in a commercial Dairy Herd Improvement Association laboratory (Midwest Dairy Records, Springfield, MO).

Calculation of Energy Balance. Energy balance (EB) was estimated on d 0, 7, and 14 according to prediction equations from NRC (2001). Daily net energy intake $\left(\mathbf{N E}_{\mathbf{I}}\right)$ from the diet was calculated as $\mathrm{NE}_{\mathrm{I}}=$ energy content of the diet $\times \mathrm{DMI} ; \mathrm{NE}_{\mathrm{M}}$ was calculated as $\mathrm{NE}_{\mathrm{M}}=\mathrm{BW}^{0.75} \times 0.08$ for multiparous cows and $\mathrm{NE}_{\mathrm{M}}=(0.96 \times \mathrm{BW})^{0.75} \times(0.1 \times \mathrm{BCS}+$ $0.65)$ for primiparous cows; $\mathrm{NE}_{\mathrm{L}}$ was calculated as $\mathrm{NE}_{\mathrm{L}}$ $=$ milk yield, $\mathrm{kg} / \mathrm{d} \times[(0.0929 \times$ fat $\%)+(0.0574 \times$ true protein $\%)+(0.0395 \times$ lactose $\%)]$; net energy for pregnancy $\left(\mathbf{N E}_{\mathbf{P}}\right)$ was calculated as $\mathrm{NE}_{\mathbf{P}}=(0.00318 \times$ days pregnant -0.0352$) \times($ calf $\mathrm{BW} / 45) \times 4.57 ; \mathrm{NE}_{\mathrm{G}}$ was calculated only for first or second lactation cows using the equation $\mathrm{NE}_{\mathrm{G}}=0.0427 \times \mathrm{BW}^{0.75} \times($ shrunk weight gain $)^{1.097}$, using values for shrunk weight gain of $0.148 \mathrm{~kg} / \mathrm{d}$ for first lactation and $0.118 \mathrm{~kg} / \mathrm{d}$ for second

Table 1. Ingredient and chemical composition of the basal diet ${ }^{1}$

\begin{tabular}{|c|c|}
\hline Item & Amount \\
\hline \multicolumn{2}{|l|}{ Ingredient, $\%$ of $\mathrm{DM}$} \\
\hline Corn silage & 35.4 \\
\hline Alfalfa haylage & 7.1 \\
\hline Alfalfa hay & 7.9 \\
\hline Corn, ground & 24.6 \\
\hline Soybean hulls, ground & 4.1 \\
\hline Brewer's grains, wet & 4.9 \\
\hline Soybean meal, $47.5 \%$ CP & 6.3 \\
\hline Amino Plus ${ }^{2}$ & 3.4 \\
\hline Blood meal & 1.0 \\
\hline Salt, white & 0.3 \\
\hline $\mathrm{CaCO}_{3}$ & 1.1 \\
\hline $\mathrm{K}_{2} \mathrm{CO}_{3}$ & 0.3 \\
\hline $\mathrm{MgO}$ & 0.2 \\
\hline $\mathrm{NaHCO}_{3}$ & 0.8 \\
\hline Dynamate $^{3}$ & 0.3 \\
\hline Trace mineral premix ${ }^{4}$ & 0.1 \\
\hline Vitamin A, D, E premix & 0.1 \\
\hline Vitamin E 20,000 & 0.1 \\
\hline Rumensin $90^{5}$ & 0.01 \\
\hline Energy Booster $100^{6}$ & 1.9 \\
\hline MetaSmart Dry ${ }^{7}$ & 0.2 \\
\hline \multicolumn{2}{|l|}{$\begin{array}{l}\text { Chemical composition, } 8 \% \text { of DM } \\
\text { unless otherwise indicated }\end{array}$} \\
\hline DM, \% & 45.6 \\
\hline $\mathrm{CP}$ & 18.4 \\
\hline Available protein & 17.5 \\
\hline Soluble protein, $\%$ of $\mathrm{CP}$ & 27.0 \\
\hline $\mathrm{ADF}$ & 22.2 \\
\hline $\mathrm{NDF}$ & 31.9 \\
\hline Lignin & 3.9 \\
\hline NFC & 37.2 \\
\hline Starch & 24.9 \\
\hline ESC,${ }^{9}$ simple sugars & 1.9 \\
\hline Crude fat & 4.7 \\
\hline Calcium & 1.1 \\
\hline Phosphorus & 0.4 \\
\hline Magnesium & 0.3 \\
\hline Potassium & 1.4 \\
\hline Sodium & 0.3 \\
\hline $\mathrm{NE}_{\mathrm{L}}, \mathrm{Mcal} / \mathrm{kg}$ & 1.7 \\
\hline DCAD, $\mathrm{mEq} / 100 \mathrm{~g}$ & 18.0 \\
\hline Total aflatoxin, ${ }^{10} \mu \mathrm{g} / \mathrm{kg}$ of DM & $\mathrm{ND}^{11}$ \\
\hline
\end{tabular}

${ }^{1}$ Values represent averages of weekly samples.

${ }^{2} \mathrm{Ag}$ Processing (Emmetsburg, IA).

${ }^{3}$ The Mosaic Co. (Plymouth, MN).

${ }^{4}$ The trace mineral premix contained $99.85 \%$ ground corn, $0.04 \%$ $\mathrm{CoSO}_{4}, 0.05 \%$ ethylenediamine dihydriodide, and $0.06 \%$ sodium selenite.

${ }^{5}$ Elanco Animal Health (Indianapolis, IN).

${ }^{6}$ Milk Specialties Global (Eden Prairie, MN).

${ }^{7}$ Adisseo (Antony, France).

${ }^{8}$ Values, provided by DairyOne Laboratories (Ithaca, NY), represent averages of samples composited weekly.

${ }^{9} \mathrm{ESC}=$ ethanol-soluble carbohydrates.

${ }^{10}$ Total aflatoxin, $\mu \mathrm{g} / \mathrm{kg}$ of $\mathrm{DM}=$ aflatoxins $\mathrm{B}_{1}+\mathrm{B}_{2}+\mathrm{G}_{1}+\mathrm{G}_{2}, \mu \mathrm{g} /$ $\mathrm{kg}$ of DM.

${ }^{11} \mathrm{ND}=$ not detected. 
lactation, respectively (Van Amburgh et al., 1998). Estimated $\mathrm{EB}$ was calculated by $\mathrm{EB}=\mathrm{NE}_{\mathrm{I}}-\mathrm{NE}_{\mathrm{M}}+\mathrm{NE}_{\mathrm{L}}$ $+\mathrm{NE}_{\mathrm{P}}+\mathrm{NE}_{\mathrm{G}}$.

\section{Aflatoxin Sampling}

Milk samples were collected into $50-\mathrm{mL}$ conical tubes during the p.m. and a.m. milkings on $\mathrm{d}-2,-1,6,7$, $8,9,10,11,12,13$, and 14. Afternoon milk samples were stored at $4^{\circ} \mathrm{C}$ until collection of morning samples, and then samples were composited on a daily basis corrected for milk yield and stored at $-20^{\circ} \mathrm{C}$ until analysis. On $\mathrm{d} 7$, the final day of the experimental period, cows were stimulated to urinate by massaging the area underneath the vulva, and urine was collected into $50-\mathrm{mL}$ conical tubes and stored at $-20^{\circ} \mathrm{C}$. Additionally, feces were collected from the rectum into plastic bags, dried at $55^{\circ} \mathrm{C}$ for $72 \mathrm{~h}$ in a forced-air oven, ground using a $0.2-\mathrm{mm}$ sieve, and stored at $-20^{\circ} \mathrm{C}$. Urine output of $\mathrm{AFM}_{1}$ was calculated as $\mathrm{AFM}_{1}$ excretion in urine, $\mu \mathrm{g} / \mathrm{d}$ $=\mathrm{AFM}_{1}$ in urine, $\mu \mathrm{g} / \mathrm{L}, \times$ urine yield, $\mathrm{kg} / \mathrm{d}$, where urine yield, $\mathrm{kg} / \mathrm{d}$ (Bannink et al., 1999) $=1.3441+$ DMI, $\mathrm{kg} / \mathrm{d} \times(1.079 \times \mathrm{Na}, \%$ of diet $\mathrm{DM}+0.5380 \times$ $\mathrm{K}, \%$ of diet DM $+0.1266 \times \mathrm{N}, \%$ of diet DM $)-$ milk yield, $\mathrm{kg} / \mathrm{d} \times(0.1216+0.0275 \times$ milk protein, \% $)$, and dietary nitrogen was calculated using the Kjeldahl method as diet $\mathrm{N}, \%=\operatorname{diet} \mathrm{CP}, \% \div 6.25$. Free fecal $\mathrm{AF}, \mu \mathrm{g} / \mathrm{d}=$ free $\mathrm{AF}$ in feces, $\mu \mathrm{g} / \mathrm{kg} \times$ feces yield, $\mathrm{kg} / \mathrm{d}$, where feces yield, $\mathrm{kg} / \mathrm{d}=\mathrm{DMI}, \mathrm{kg} / \mathrm{d} \times \operatorname{diet} \mathrm{TDN}, \%$.

Laboratory Analysis of $A F M_{1}$. Milk samples were thawed, then centrifuged at $1,875 \times g$ at $4^{\circ} \mathrm{C}$ for $15 \mathrm{~min}$, and the fat layer was removed. Ten milliliters of skim milk samples were passed through AFLAPREP M immunoaffinity cleanup columns (R-Biopharm Rhone Ltd., Glasgow, Scotland), columns were washed with $10 \mathrm{~mL}$ of $\mathrm{PBS}$, and $\mathrm{AFM}_{1}$ was then eluted from the columns with $1.5 \mathrm{~mL}$ of acetonitrile, followed by $1.5 \mathrm{~mL}$ of water. Eluates were combined, placed in autosampler vials, and analyzed by HPLC with fluorescence detection. The HPLC system (Hitachi High Technologies America Inc., Schaumburg, IL) consisted of a Hitachi model L-7100 pump with a Hitachi Model L-7485 fluorescence detector $(365 \mathrm{~nm}$ excitation and $440 \mathrm{~nm}$ emission), a Hitachi Model L-7200 autosampler with Hitachi D-7000 data acquisition interface, and Concert Chrom software on a microcomputer. The HPLC column was a $150 \times 4.6 \mathrm{~mm}$ reversed-phase HyperClone $3-\mu \mathrm{m} \mathrm{C}_{18}$ BDS column (Phenomenex, Torrance, CA) with a $\mathrm{C}_{18}$ SecurityGuard precolumn (Phenomenex). The mobile phase was acetonitrile:methanol:water (15:15:70) run at $1 \mathrm{~mL} / \mathrm{min}$. The injection volume was $50 \mu \mathrm{L}$ for all standards and samples. The detection limit was set at $40 \mathrm{ng} / \mathrm{kg}$ of $\mathrm{AFM}_{1}$. Urine samples were thawed, centrifuged at $1,875 \times g$ at $4^{\circ} \mathrm{C}$ for $15 \mathrm{~min}$, and $2 \mathrm{~mL}$ of the urine was analyzed for $\mathrm{AFM}_{1}$ using the same procedure described above.

Laboratory Analysis of Fecal Aflatoxins. Fecal samples were thawed and quantified for total $\mathrm{AF}\left(\mathrm{B}_{1}+\right.$ $\mathrm{B}_{2}+\mathrm{G}_{1}+\mathrm{G}_{2}$ ) using HPLC. Five grams of each fecal sample was extracted with $80 \%$ aqueous methanol for $30 \mathrm{~min}$ and $2 \mathrm{~mL}$ of supernatant was combined with 10 $\mathrm{mL}$ of PBS buffer and passed through EASI-EXTRACT aflatoxin immunoaffinity columns (R-Biopharm Inc., Washington, MO). Columns were washed with $10 \mathrm{~mL}$ of PBS, and AF was then eluted from the columns with $1.5 \mathrm{~mL}$ of methanol, followed by $1.5 \mathrm{~mL}$ of water. Eluates were combined, placed in autosampler vials, and analyzed by HPLC with fluorescence detection. The HPLC system was an Elite LaChrom (Hitachi High Technologies America Inc.) with model L-2485 fluorescence detector, model L-2000 autosampler, and Hyperclone $3 \mu \mathrm{m} 100 \times 4.6 \mathrm{~mm}$ column, fitted with a KobraCell (R-Biopharm Rhône Ltd., Glasgow, UK) at $50 \mu \mathrm{A}$. The mobile phase consisted of $2,300 \mathrm{~mL}$ of distilled water, $500 \mathrm{~mL}$ of methanol, $500 \mathrm{~mL}$ of acetonitrile, $1.2 \mathrm{~g}$ of potassium bromide, and $360 \mu \mathrm{L}$ of nitric acid. The flow rate was stabilized at $0.9 \mathrm{~mL} / \mathrm{min}$ and the detector was set for excitation of $360 \mathrm{~nm}$ and emission of $440 \mathrm{~nm}$. A total AF standard $\left(\mathrm{B}_{1}, \mathrm{~B}_{2}, \mathrm{G}_{1}\right.$, and $\mathrm{G}_{2}$, in a ratio of $4 / 1 / 4 / 1$, Trilogy Analytical Laboratory, Washington, MO), $5 \mu \mathrm{g} / \mathrm{mL}$ in acetonitrile, was used to establish peak retention times. The detection limit for all $\mathrm{AF}$ was $5 \mathrm{ng} / \mathrm{mL}$.

\section{Statistical Analysis}

Data were analyzed using SAS 9.4 (SAS Institute Inc., Cary, NC). Variables were first tested for normality using the UNIVARIATE procedure. Somatic cell count data were $\log _{10}$-transformed, but all other variables were normally distributed. Next, data were analyzed as a randomized complete block design using the MIXED procedure with repeated statement. The statistical model included fixed effects of treatment, time, and their interaction. Treatment within block was the random effect. Time was the specific term for the repeated statement, with cow within treatment and block as subject. Either autoregressive order 1 or compound symmetry were the covariance structures selected based on the lowest Akaike's information criterion (Littell et al., 1998). Averaged data from d -1 and 0 of the trial (adaptation period) were used as covariates for each variable. Three orthogonal contrasts were used to interpret treatment effects: (1) absence versus presence of $\mathrm{AF}$ in the diet ( $\mathrm{NC}$ vs. $\mathrm{PC}, \mathrm{TN}$, and $\mathrm{UP})$, (2) presence of $\mathrm{AF}$ alone versus presence of $\mathrm{AF}$ and additives (PC vs. TN and UP), and (3) Toxy-Nil versus Unike Plus (TN vs. UP). The PDIFF option was 
used to separate least squares means. Significance was declared at $P \leq 0.05$ and a tendency was noted when $0.05<P \leq 0.10$. Results are reported as least squares means \pm standard error of the mean.

\section{RESULTS AND DISCUSSION}

Average intakes of $\mathrm{AF}$ and additives are shown in Table 2. The dosage of AF (2.8 mg/cow per d) allocated to cows on PC, TN, and UP treatments was intended to provide a dietary concentration of $100 \mu \mathrm{g} / \mathrm{kg}$ of diet DM, based on expected DMI of $28 \mathrm{~kg} / \mathrm{d}$. Actual DMI did not differ among treatments but was slightly lower than projected. This resulted in calculated dietary concentrations of AF intake that were similar among the 3 treatments that included AF, all of which were higher than NC. Dietary concentrations of AF averaged $106.5,107.6$, and $102.5 \pm 2.9 \mu \mathrm{g} / \mathrm{kg}$ of DM for PC, TN, and UP, respectively (Table 2). Concentrations of AF consumed differed slightly over time and there was an interaction of treatment and time, both due to daily variation in DMI. Intakes of TN and UP were similar, averaging 0.4 and $0.4 \pm 0.1 \%$ of diet DM, respectively $(P=0.09)$. Additive intake also varied over time and there was an interaction of treatment and time (Table 2). Like AF intake, these differences reflected variation in daily DMI (Table 3). Examination of daily AF, TN, and UP intakes confirmed that they varied together over time (data not shown).

Dietary AF that is absorbed from the gut is metabolized in the liver to form $\mathrm{AFM}_{1}$, which is the form secreted into milk or voided in urine (Kuilman et al., 2000). As expected, cows fed AF secreted substantial quantities of $\mathrm{AFM}_{1}$ into their milk. Concentrations of $\mathrm{AFM}_{1}$ in milk were consistent with those reported by Kutz et al. (2009), who also fed AF at about $100 \mu \mathrm{g} / \mathrm{kg}$ of DM, but were markedly higher than those reported by others (Queiroz et al., 2012; Ogunade et al., 2016), who fed about $75 \mu \mathrm{g}$ of $\mathrm{AF} / \mathrm{kg}$ of $\mathrm{DM}$, indicating a large difference in absorption, probably due in part to concentrations of AF fed. Inclusion of either TN or UP in the diet significantly reduced $(P<0.01)$ the concentration and mass of $\mathrm{AFM}_{1}$ secreted in milk by 50 to $60 \%$, relative to cows on PC treatment, and no statistical difference was observed between TN and UP. Both of these variables were significantly affected by time and time by treatment interactions (Table 2). As shown in Figure 1, concentration and mass of $\mathrm{AFM}_{1}$ in milk decreased rapidly after withdrawal of AF from diets, as reported previously (Masoero et al., 2007; Queiroz et al., 2012; Ogunade et al., 2016). For TN and UP, concentrations dropped below the FDA limit of $0.5 \mu \mathrm{g} /$ $\mathrm{kg}$ of milk within $24 \mathrm{~h}(\mathrm{~d} 8)$ and approached $0 \mu \mathrm{g} / \mathrm{kg}$ of milk by $48 \mathrm{~h}(\mathrm{~d} 9)$, whereas concentration and mass in
PC appeared to decline more rapidly but still required $1 \mathrm{~d}$ more than TN and UP to drop below the FDA limit (d 9) or approach zero (d 10). It is clear from Figure 1 that the main difference between treatments with (TN and UP) or without (PC) additives is the concentration or mass of $\mathrm{AFM}_{1}$ in milk on d 7 and 8, presumably reflecting lower absorption of $\mathrm{AF}$ from the gut in $\mathrm{TN}$ and UP due to binding effects of these additives. This is supported by the much lower transfer of AF from feed to milk in the presence of these additives, which did not vary over time (Table 2). Furthermore, expressing clearance of $\mathrm{AFM}_{1}$ via milk as a daily percentage of the average content in milk on $\mathrm{d} 6$ and 7 revealed no difference between PC, TN, and UP, as shown clearly in Figure 2. These results suggest that TN and UP did not alter metabolism of absorbed $\mathrm{AF}$ to $\mathrm{AFM}_{1}$, nor its transfer into, and secretion from, the mammary glands but rather reduced uptake from the gut. This is in agreement with the similar clearance of $\mathrm{AFM}_{1}$ in the presence or absence of a mycotoxin-sequestering agent found by Queiroz et al. (2012) but is in contrast to the study of Ogunade et al. (2016), who reported that 3 mycotoxin-sequestering agents evaluated did not reduce $\mathrm{AFM}_{1}$ concentrations in milk during the dosing period but hastened their decline postdosing.

In the present study, concentrations of $\mathrm{AFM}_{1}$ in urine were much higher than those in milk, and were also reduced $(P<0.03)$ by $\mathrm{TN}$ and UP relative to $\mathrm{PC}$. Moreover, they did not differ between TN and UP (Table 2). On the other hand, the reductions in concentration of $\mathrm{AFM}_{1}$ in urine of $\mathrm{TN}$ or $\mathrm{UP}$, relative to $\mathrm{PC}$, did not closely match the corresponding reductions in milk $\mathrm{AFM}_{1}$, perhaps because urine was only collected at a single time point. Few others have investigated urinary excretion of $\mathrm{AFM}_{1}$, but Sulzberger et al. (2017) also found higher concentrations of $\mathrm{AFM}_{1}$ in urine than milk and reported that, whereas dietary additives reduced $\mathrm{AFM}_{1}$ in milk, there was no such effect on urinary concentrations. Similarly, Weatherly et al. (2018) found higher concentrations of $\mathrm{AFM}_{1}$ in urine compared with milk, although the dietary additives tested in that study were not effective in reducing concentrations of $\mathrm{AFM}_{1}$ in milk or urine. It is clear that $\mathrm{AFM}_{1}$ is excreted via urine to a greater extent than via milk, but factors regulating the relative uptake by kidney and mammary gland, and how they may be affected by dietary additives such as mycotoxins-sequestering agents, are unknown. We also found that the sequestrants reduced concentrations of $\mathrm{AF}$ in feces, relative to PC (Table 2). This result is counterintuitive to the assumption that the mycotoxin-sequestering additives reduced uptake by sequestering $\mathrm{AF}$ in the gut but is probably explained by additive-bound AF being undetectable by our analysis as a result of the tight binding 
MYCOTOXIN SEQUESTRANTS REDUCE AFLATOXIN EXCRETION

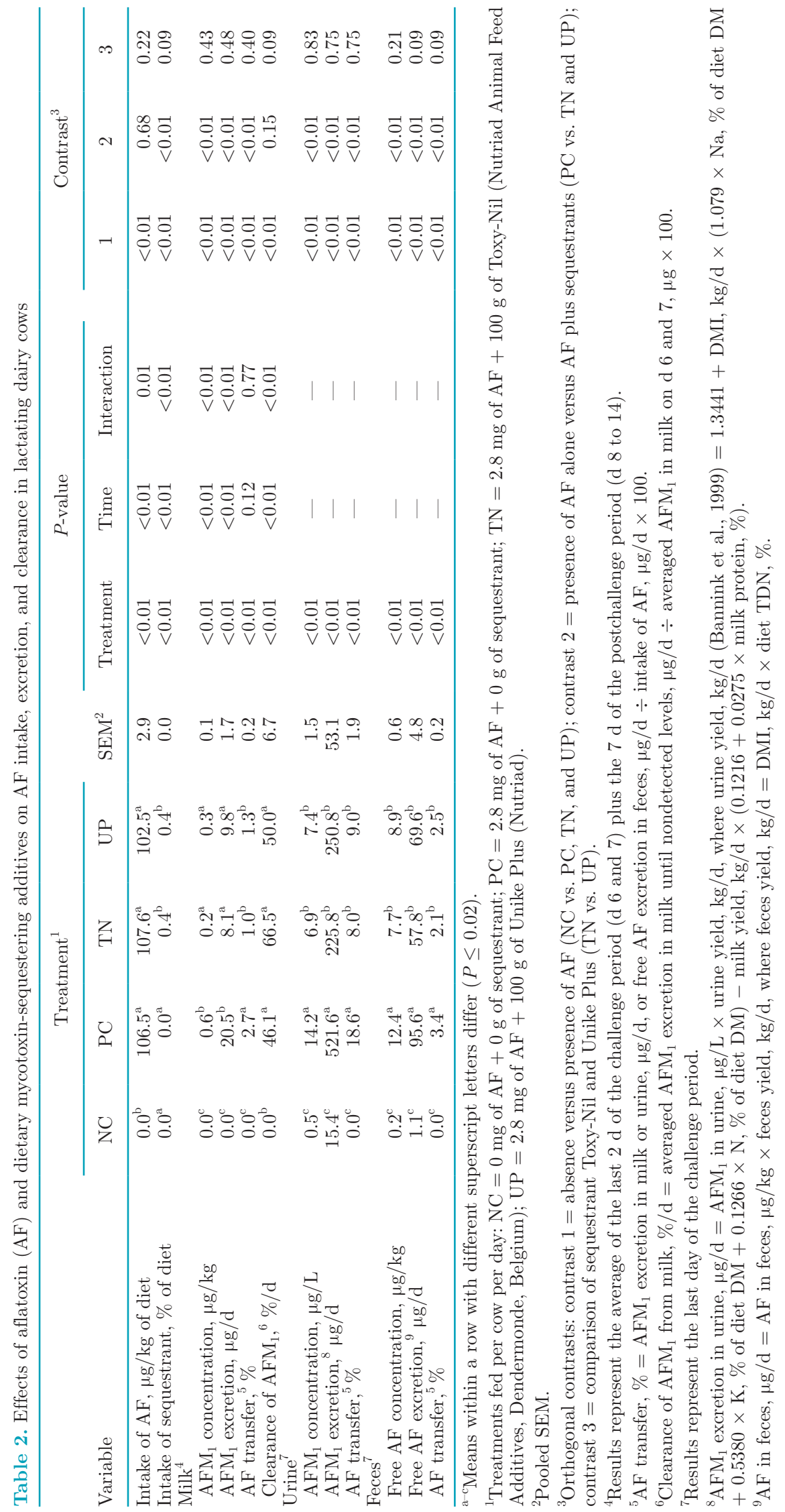

Journal of Dairy Science Vol. 102 No. 7, 2019 
RODRIGUES ET AL.

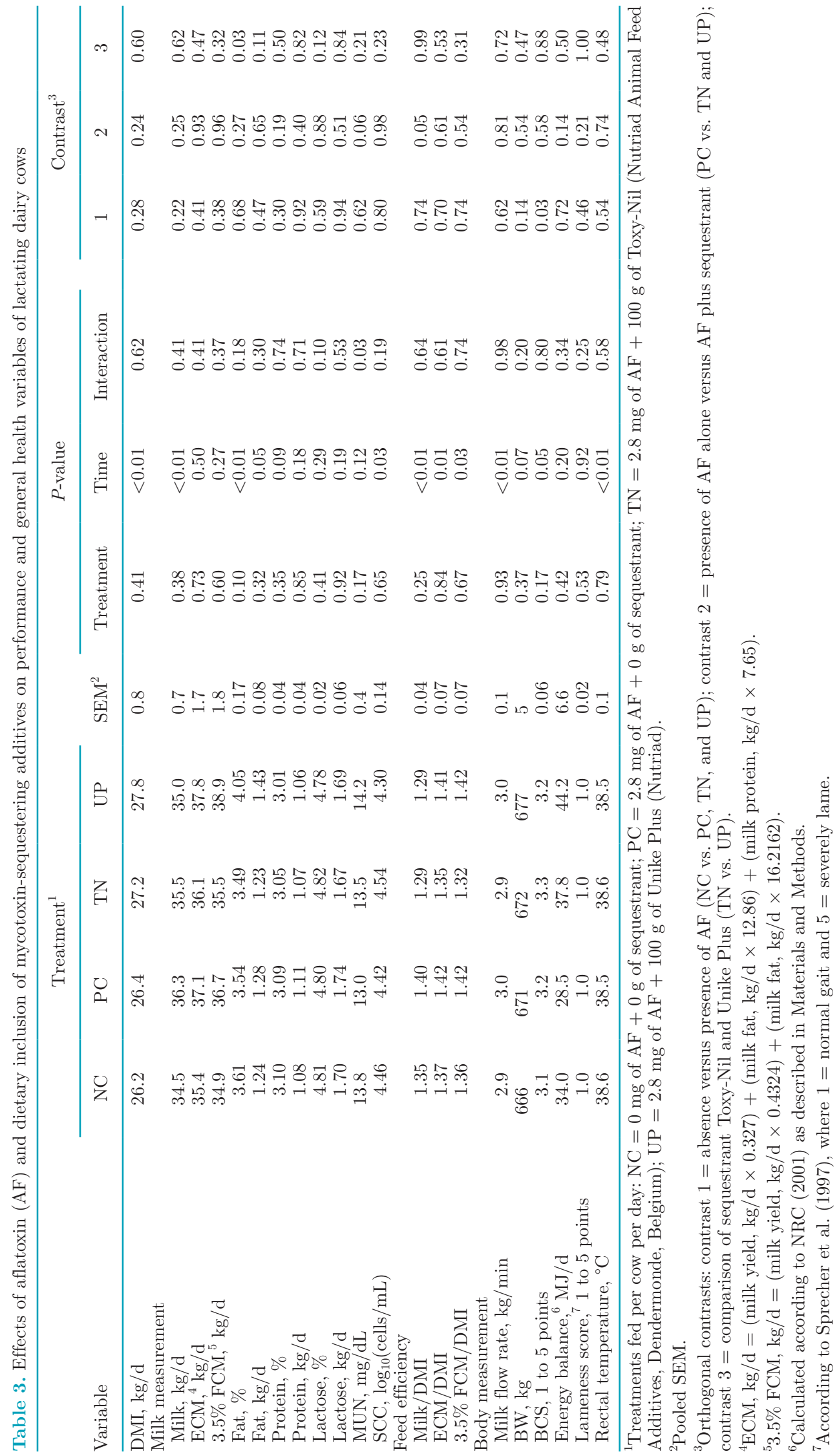



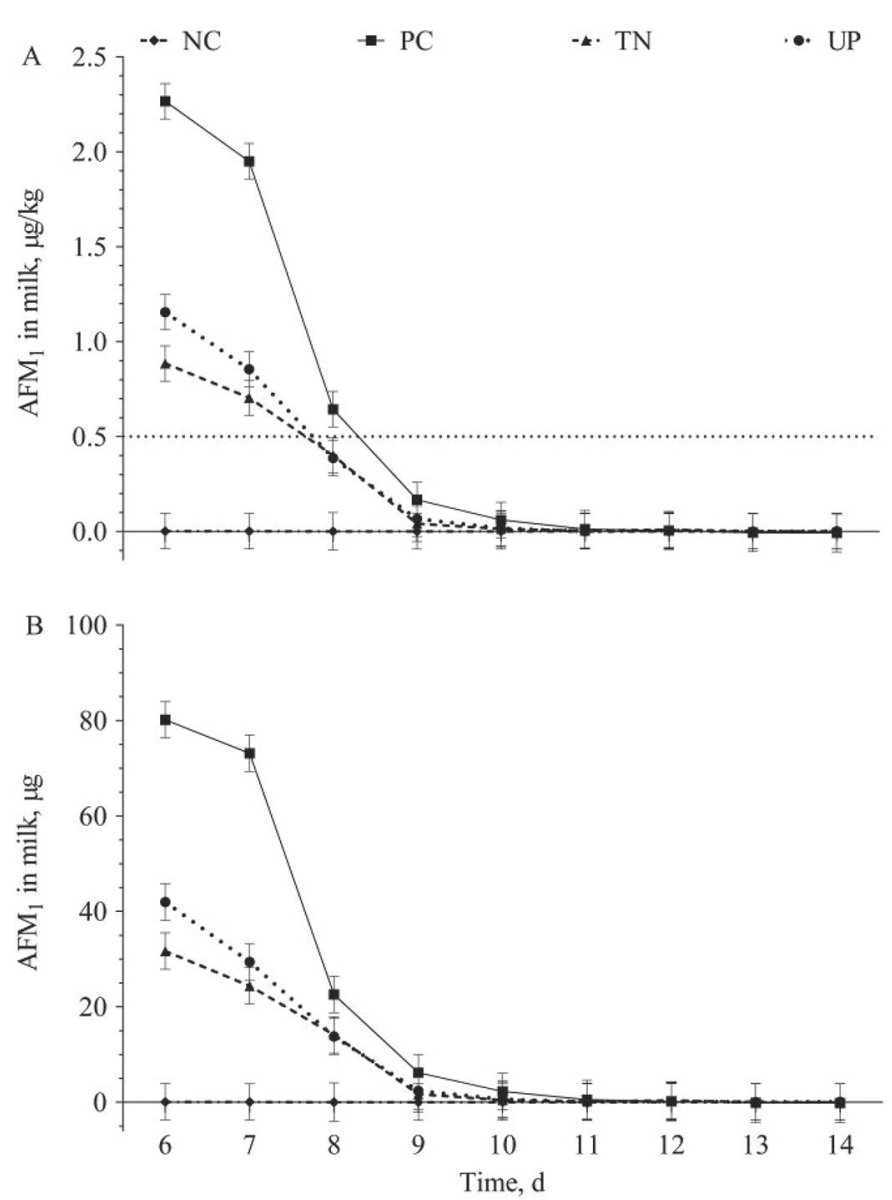

Figure 1. Time course of changes in concentrations of aflatoxin (AF) $\mathrm{M}_{1}$ in milk of control cows (NC) or cows challenged with $2.8 \mathrm{mg} / \mathrm{d}$ of dietary AF alone (PC) or with dietary mycotoxin-sequestering additives Toxy-Nil (TN; Nutriad Animal Feed Additives, Dendermonde, Belgium) or Unike Plus (UP; Nutriad). Results shown are the last 2 $\mathrm{d}$ of $\mathrm{AF}$ challenge (d 6 and 7 ) and the $7 \mathrm{~d}$ postchallenge, shown as $\mathrm{d}$ 8 to 14 . The dotted line at $0.5 \mu \mathrm{g} / \mathrm{mL}$ represents the FDA limit for $\mathrm{AFM}_{1}$ residues in milk. Each data point represents the mean of 8 cows. Effects of treatment, time, and their interaction were significant $(P \leq$ 0.001). Error bars represent SEM.

of $\mathrm{AF}$ to the additive, and the failure of the extraction method to release AF from the AF-additive complex. This conclusion is supported by the study of Phillips et al. (1988) who reported that once radiolabeled AF was sorbed to a mycotoxin-sequestering additive (aluminosilicate), it remained bound to the additive even after a series of eluotropic solvents were used to extract the AF. Sulzberger et al. (2017) reported that fecal concentrations of AF decreased with increasing dose of clays in the diet and suggested that clay-bound AF may be undetectable. Recently, Weatherly et al. (2018) also reported that a yeast and bentonite clay-based adsorbent tended to reduce AF in feces. Further studies on the effects of mycotoxin-sequestering additives on metabolism and clearance of $\mathrm{AFM}_{1}$ via milk or urine appear warranted.
There is a marked difference in the efficacy of various mycotoxin-sequestering additives to reduce AF transfer from feed into milk. Based on studies in vitro, AF binding efficiency varies from 20 to $100 \%$, depending on the product tested and on presence or absence of other compounds in incubation fluid (Diaz et al., 2002; Moschini et al., 2008; Gallo and Masoero, 2010). The same holds true in vivo, with results depending on the dosage and mode of AF delivery and on the specific additive and dosage tested. For example, Kutz et al. (2009) reported that of 3 mycotoxin-sequestering additives tested, 2 significantly reduced $\mathrm{AFM}_{1}$ in milk, and 1 had no effect. Ogunade et al. (2016) tested 3 sequestering agents and found that none reduced $\mathrm{AFM}_{1}$ in milk during $\mathrm{AF}$ challenge, but all hastened the decline in concentrations postchallenge. We found that both additives markedly reduced the percentage of AF transferred into milk, from $2.7 \%$ in PC to 1.0 and $1.3 \pm 0.2 \%$ for TN and UP, reductions of 63 and $52 \%$, respectively $(P<0.001)$. The reduction in percentage transfer is similar to that reported for other mycotoxin-sequestering additives (transfers of 0.32 to $3.68 \%$, reductions of $27-70 \%$; Kutz et al., 2009; Sulzberger et al., 2017; Xiong et al., 2018), but is comparatively high, indicating the efficacy of TN or UP in reducing AF residues in milk.

Concentrations of $\mathrm{AF}$ in the diet were about 5 times greater than the FDA limit for AF in feedstuffs and the concentration of $\mathrm{AFM}_{1}$ in milk and urine was de-

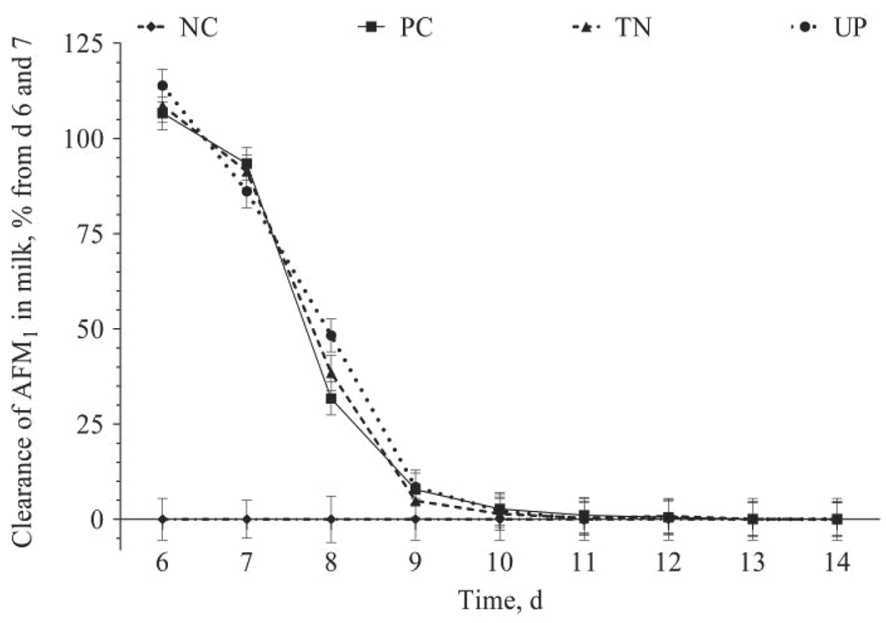

Figure 2. Clearance of aflatoxin $(\mathrm{AF}) \mathrm{M}_{1}$ via secretion into milk of control cows (NC) or cows challenged with $2.8 \mathrm{mg} / \mathrm{d}$ of dietary AF alone (PC) or with dietary mycotoxin-sequestering additives ToxyNil (TN; Nutriad Animal Feed Additives, Dendermonde, Belgium) or Unike Plus (UP; Nutriad). Results represent the mass of $\mathrm{AFM}_{1}$ secreted into milk on each day as a percentage of the average mass of $\mathrm{AFM}_{1}$ in milk on the last $2 \mathrm{~d}$ of AF challenge (d 6 and 7). Results shown are the last $2 \mathrm{~d}$ of AF challenge ( $\mathrm{d} 6$ and 7 ) and the $7 \mathrm{~d}$ postchallenge, shown as $\mathrm{d} 8$ to 14 . Each data point represents the weighted mean of p.m. and a.m. milkings for 8 cows. The overall treatment effect was significant $(P<0.001)$ due to NC differing from PC, TN, and UP, but the latter 3 treatments did not differ. Error bars represent SEM. 
pendent on feeding of $\mathrm{AF}$ and supplemental TN or UP, in effect creating an apparent dose relationship of $\mathrm{AF}$ uptake. In spite of this, there were no differences in DMI, milk yield, feed efficiency, or milk flow rate $(P$ $\geq 0.25$; Table 3 ), with the exception of the comparison of PC to the mean of TN and UP for feed efficiency $(P=0.05)$. Our results were consistent with others who found no effect on DMI and milk yield when cows received dietary AF at 75 to $112 \mu \mathrm{g} / \mathrm{kg}$ (Kutz et al., 2009; Queiroz et al., 2012; Xiong et al., 2018), although effects of mycotoxin binders on DMI seem to be dose dependent (Sulzberger et al., 2017). In contrast, reduction of DMI was observed at a concentration of 170 $\mu \mathrm{g} / \mathrm{kg}$ of $\mathrm{AFB}_{1}$ in diet DM (Stroud, 2006). Others reported that $\mathrm{AF}$ challenge tended to decrease 3.5\% FCM and ECM (Sulzberger et al., 2017), and tended to reduce indices of feed efficiency because of differences in milk composition (Ogunade et al., 2016; Sulzberger et al., 2017). Our results showed no effect of AF alone or with TN and UP on milk composition (Table 3), with 2 exceptions; there were tendencies $(P=0.10)$ for a treatment effect on milk fat percentage, which was due to a difference $(P=0.03)$ between groups TN and $\mathrm{UP}$, and for an interactive effect of treatment and time on lactose content. We have no explanation for these findings, but some have reported indications of effects on fat percent (Maki et al., 2017; Sulzberger et al., 2017), whereas other studies did not find a difference in milk fat content in cows consuming AF and mycotoxinsequestering additives (Queiroz et al., 2012; Xiong et al., 2015; Weatherly et al., 2018). Sulzberger et al. (2017) reported a negative linear effect of supplemental clay dosage on milk lactose contents and yield, relative to AF alone. However, that study also found a similar negative effect on milk yield. It would appear that such results reflect subtle and unexplained effects of $\mathrm{AF}$ and sorbents or experimental variation. We also found an interactive effect of treatment and time on MUN $(P=$ 0.03; Table 3), apparently due to a difference between $\mathrm{PC}$ versus TN and UP $(P=0.06)$. Concentrations of MUN are typically related to levels of dietary CP (Reid et al., 2015) and reflect protein metabolism but 3 other studies on $\mathrm{AF}$ and mycotoxin binders did not find any effect on MUN (Maki et al., 2016; Sulzberger et al., 2017; Weatherly et al., 2018).

Previous studies have variously reported effects of $\mathrm{AF}$ and mycotoxin-sequestering additives on DMI, milk yield, markers of immune function, or metabolism (Queiroz et al., 2012; Maki et al., 2016; Ogunade et al., 2016), and recently, on cow behavior (Sulzberger et al., 2017). Thus, we evaluated several variables related to general cow health and performance. Treatments had no effects on BW, EB, lameness score, rectal temperature, or milk flow rate (Table 3). The relatively short duration of our experiment made it unlikely to detect changes in variables such as BW, BCS, and lameness. Nevertheless, DMI $(P<0.01)$, BCS $(P=0.05)$, BW $(P=0.07)$, and rectal temperature $(P<0.001)$ were all affected by time. In addition, although there was no overall treatment effect, the orthogonal contrast comparing the absence of dietary $\mathrm{AF}$ to the 3 treatments that included $\mathrm{AF}$ (NC vs. PC, TN, and UP) was significant for BCS $(P=0.03)$. Most other studies on effects of dietary AF have not examined BW or BCS but 2 recent reports found no effects (Maki et al., 2016; Sulzberger et al., 2017). In our experiment, cows were in mid-lactation and both milk yield and DMI declined over time (data not shown), thus it is not clear why cows increased in BCS and tended to gain BW, but those effects were small and probably of no biological significance.

\section{CONCLUSIONS}

We conclude that inclusion of $100 \mathrm{~g} /$ cow per d of TN or UP in the diet significantly reduced (50 to $60 \%$ ) $\mathrm{AFM}_{1}$ concentrations in milk of cows consuming TMR containing approximately 5 times the FDA limit of 20 $\mu \mathrm{g}$ of $\mathrm{AF} / \mathrm{kg}$ of diet DM. Supplementation with TN or UP also reduced the time required postchallenge for $\mathrm{AFM}_{1}$ concentrations to drop below the FDA limit for milk. Results suggest that both TN and UP reduced absorption of AF from the gastrointestinal tract.

\section{ACKNOWLEDGMENTS}

Financial support provided by Nutriad International is gratefully acknowledged.

\section{REFERENCES}

Abdel-Wahhab, M. A., S. A. Nada, and F. A. Khalil. 2002. Physiological and toxicological responses in rats fed aflatoxin-contaminated diet with or without sorbent materials. Anim. Feed Sci. Technol. 97:209-219.

Applebaum, R. S., R. E. Brackett, D. W. Wiseman, and E. H. Marth. 1982. Responses of dairy cows to dietary aflatoxin: Feed intake and yield, toxin content, and quality of milk of cows treated with pure and impure aflatoxin. J. Dairy Sci. 65:1503-1508.

Bannink, A., H. Valk, and A. M. Van Vuuren. 1999. Intake and excretion of sodium, potassium, and nitrogen and the effects on urine production by lactating dairy cows. J. Dairy Sci. 82:1008-1018.

Battacone, G., A. Nudda, A. Cannas, A. Cappio Borlino, G. Bomboi, and G. Pulina. 2003. Excretion of aflatoxin $\mathrm{M}_{1}$ in milk of dairy ewes treated with different doses of aflatoxin $\mathrm{B}_{1}$. J. Dairy Sci. $86: 2667-2675$

Bennett, J. W., and M. Klich. 2003. Mycotoxins. Clin. Microbiol. Rev. $16: 497-516$.

Carraro, A., A. De Giacomo, M. L. Giannossi, L. Medici, M. Muscarella, L. Palazzo, V. Quaranta, V. Summa, and F. Tateo. 2014. Clay minerals as adsorbents of aflatoxin $\mathrm{M}_{1}$ from contaminated milk and effects on milk quality. Appl. Clay Sci. 88-89:92-99. 
Dairy Records Management Systems. 2014. DHI Glossary. Dairy Records Management Systems, Raleigh, NC.

Diaz, D. E., W. M. Hagler, J. T. Blackwelder, J. A. Eve, B. A. Hopkins, K. L. Anderson, F. T. Jones, and L. W. Whitlow. 2004. Aflatoxin Binders II: Reduction of aflatoxin $\mathrm{M}_{1}$ in milk by sequestering agents of cows consuming aflatoxin in feed. Mycopathologia 157:233-241.

Diaz, D. E., W. M. Hagler, B. A. Hopkins, and L. W. Whitlow. 2002. Aflatoxin Binders I: In vitro binding assay for aflatoxin $\mathrm{B}_{1}$ by several potential sequestering agents. Mycopathologia 156:223-226.

EFSA. 2004. Opinion of the scientific panel on contaminants in the food chain on a request from the commission related to aflatoxin B1 as undesirable substance in animal feed. EFSA J. 39:1-27.

FDA. 2000. Guidance for industry and other stakeholders: Toxicological principles for the safety assessment of food ingredients. Redbook $3: 1-286$.

Gallo, A., and F. Masoero. 2010. In vitro models to evaluate the capacity of different sequestering agents to adsorb aflatoxins. Ital. J. Anim. Sci. 9:109-116.

Gallo, A., M. Moschini, and F. Masoero. 2008. Aflatoxins absorption in the gastro-intestinal tract and in the vaginal mucosa in lactating dairy cows. Ital. J. Anim. Sci. 7:53-63.

Helferich, W. G., W. N. Garrett, D. P. Hsieh, and R. L. Baldwin. 1986. Feedlot performance and tissue residues of cattle consuming diets containing aflatoxins. J. Anim. Sci. 62:691-696.

IARC. 2002. Some traditional herbal medicines, some mycotoxins, naphthalene and styrene. Pages 171-300 in Monographs on the Evaluation of Carcinogenic Risks to Humans. Volume 82. International Agency for Research on Cancer, Lyon, France.

Jiang, Y., P. E. Jolly, W. O. Ellis, J. S. Wang, T. D. Phillips, and J. H. Williams. 2005. Aflatoxin $B_{1}$ albumin adduct levels and cellular immune status in Ghanaians. Int. Immunol. 17:807-814.

Kuilman, M. E., R. F. Maas, and J. Fink-Gremmels. 2000. Cytochrome P450-mediated metabolism and cytotoxicity of aflatoxin $\mathrm{B}_{1}$ in bovine hepatocytes. Toxicol. In Vitro 14:321-327.

Kutz, R. E., J. D. Sampson, L. B. Pompeu, D. R. Ledoux, J. N. Spain, M. Vázquez-Añón, and G. E. Rottinghaus. 2009. Efficacy of Solis, NovasilPlus, and MTB-100 to reduce aflatoxin $\mathrm{M}_{1}$ levels in milk of early to mid lactation dairy cows fed aflatoxin $\mathrm{B}_{1}$. J. Dairy Sci. 92:3959-3963.

Littell, R. C., P. R. Henry, and C. B. Ammerman. 1998. Statistical analysis of repeated measures data using SAS procedures. J. Anim. Sci. 76:1216-1231.

Maki, C. R., S. Haney, M. Wang, S. H. Ward, B. J. Rude, R. H. Bailey, R. B. Harvey, and T. D. Phillips. 2017. Calcium montmorillonite clay for the reduction of aflatoxin residues in milk and dairy products. J. Dairy Vet. Sci. 2:1-8.

Maki, C. R., A. D. Thomas, S. E. Elmore, A. A. Romoser, R. B. Harvey, H. A. Ramirez-Ramirez, and T. D. Phillips. 2016. Effects of calcium montmorillonite clay and aflatoxin exposure on dry matter intake, milk production, and milk composition. J. Dairy Sci. 99:1039-1046.

Marin, D. E., I. Taranu, R. P. Bunaciu, F. Pascale, D. S. Tudor, N. Avram, M. Sarca, I. Cureu, R. D. Criste, V. Suta, and I. P. Oswald. 2002. Changes in performance, blood parameters, humoral and cellular immune responses in weanling piglets exposed to low doses of aflatoxin. J. Anim. Sci. 80:1250-1257.

Masoero, F., A. Gallo, M. Moschini, G. Piva, and D. Diaz. 2007. Carryover of aflatoxin from feed to milk in dairy cows with low or high somatic cell counts. Animal 1:1344-1350.

Moschini, M., A. Gallo, G. Piva, and F. Masoero. 2008. The effects of rumen fluid on the in vitro aflatoxin binding capacity of different sequestering agents and in vivo release of the sequestered toxin. Anim. Feed Sci. Technol. 147:292-309.

Moschini, M., F. Masoero, A. Gallo, and D. Diaz. 2007. Mucosal absorption of aflatoxin $\mathrm{B}_{1}$ in lactating dairy cows. Ital. J. Anim. Sci. $6: 324-326$.

NRC. 2001. Nutrient Requirements of Dairy Cattle. 7th rev. ed. Natl. Acad. Press, Washington, DC.
Ogunade, I. M., K. G. Arriola, Y. Jiang, J. P. Driver, C. R. Staples, and A. T. Adesogan. 2016. Effects of 3 sequestering agents on milk aflatoxin $\mathrm{M}_{1}$ concentration and the performance and immune status of dairy cows fed diets artificially contaminated with aflatoxin $B_{1}$. J. Dairy Sci. 99:6263-6273.

Phillips, T. D., L. F. Kubena, R. B. Harvey, D. R. Taylor, and N. D. Heidelbaugh. 1988. Hydrated sodium calcium aluminosilicate: A high affinity sorbent for aflatoxin. Poult. Sci. 67:243-247.

Queiroz, O. C. M., J. H. Han, C. R. Staples, and A. T. Adesogan. 2012. Effect of adding a mycotoxin-sequestering agent on milk aflatoxin $\mathrm{M}_{1}$ concentration and the performance and immune response of dairy cattle fed an aflatoxin $\mathrm{B}_{1}$-contaminated diet. J. Dairy Sci. 95:5901-5908

Ramos, A. J., and E. Hernández. 1997. Prevention of aflatoxicosis in farm animals by means of hydrated sodium calcium aluminosilicate addition to feedstuffs: A review. Anim. Feed Sci. Technol. 65:197-206.

Reid, M., M. O. Donovan, C. T. Elliott, J. S. Bailey, C. J. Watson, S. T. J. Lalor, B. Corrigan, M. A. Fenelon, and E. Lewis. 2015. The effect of dietary crude protein and phosphorus on grass-fed dairy cow production, nutrient status, and milk heat stability. J. Dairy Sci. 98:517-531.

Richard, J. L., G. A. Payne, A. E. Desjardins, C. Maragos, W. P. Norred III, J. J. Pestka, T. D. Phillips, H. P. V. Egmond, P. J. Vardon, T. B. Whitaker, and G. Wood. 2003. Mycotoxins: Risks in Plant, Animal, and Human Systems. Council for Agricultural Science and Technology, Task force report No. 139. 199 pp.

Sprecher, D. J., D. E. Hostetler, and J. B. Kaneene. 1997. A lameness scoring system that uses posture and gait to predict dairy cattle reproductive performance. Theriogenology 47:1179-1187.

Squire, R. A. 1981. Ranking animal carcinogens: A proposed regulatory approach. Science 214:877-880.

Streit, E., K. Naehrer, I. Rodrigues, and G. Schatzmayr. 2013. Mycotoxin occurrence in feed and feed raw materials worldwide: Longterm analysis with special focus on Europe and Asia. J. Sci. Food Agric. 93:2892-2899.

Stroud, J. S. 2006. The effect of feed additives on aflatoxin in milk of dairy cows fed aflatoxin-contaminated diets. MS Thesis. Department of Animal Science, North Carolina State University, Raleigh.

Sulzberger, S. A., S. Melnichenko, and F. C. Cardoso. 2017. Effects of clay after an aflatoxin challenge on aflatoxin clearance, milk production, and metabolism of Holstein cows. J. Dairy Sci. 100:18561869.

Van Amburgh, M. E., D. G. Fox, D. M. Galton, D. E. Bauman, and L. E. Chase. 1998. Evaluation of National Research Council and Cornell Net Carbohydrate and Protein Systems for predicting requirements of Holstein heifers. J. Dairy Sci. 81:509-526.

Weatherly, M. E., R. T. Pate, G. E. Rottinghaus, F. O. Roberti Filho, and F. C. Cardoso. 2018. Physiological responses to a yeast and clay-based adsorbent during an aflatoxin challenge in Holstein cows. Anim. Feed Sci. Technol. 235:147-157.

Wildman, E. E., G. M. Jones, P. E. Wagner, and R. L. Boman. 1982. A dairy body condition scoring system and its relationship to selected production characteristics. J. Dairy Sci. 65:495-501.

Wogan, G. N. 1999. Aflatoxin as a human carcinogen. Hepatology 30:573-575.

Xiong, J. L., Y. M. Wang, T. D. Nennich, Y. Li, and J. X. Liu. 2015. Transfer of dietary aflatoxin $B_{1}$ to milk aflatoxin $M_{1}$ and effect of inclusion of adsorbent in the diet of dairy cows. J. Dairy Sci. 98:2545-2554.

Xiong, J. L., Y. M. Wang, H. L. Zhou, and J. X. Liu. 2018. Effects of dietary adsorbent on milk aflatoxin $\mathrm{M}_{1}$ content and the health of lactating dairy cows exposed to long-term aflatoxin $\mathrm{B}_{1}$ challenge. J. Dairy Sci. 101:8944-8953.

Yiannikouris, A., and J.-P. Jouany. 2002. Mycotoxins in feeds and their fate in animals: a review. Anim. Res. 51:81-99. 